\title{
Design and development of a CNC micro blanking machine with mechanical and control validation investigation
}

\author{
Didin Zakariya Lubis $^{1 *}$, Suprayitno ${ }^{1}$, Yanuar Rohmat Aji Pradana ${ }^{1}$, and Khoiruddin Asfani ${ }^{2}$ \\ ${ }^{1}$ Mechanical Engineering Department, State University of Malang, 65145 Malang, Indonesia \\ ${ }^{2}$ Electrical Engineering Department, State University of Malang, 65145 Malang, Indonesia
}

\begin{abstract}
The increasing of needs on several industrial fields such as medical, electrical and mechanical field require accurate dimensional and geometrical function and efficiency in a product, one example being the manufacture of micro-hole and micropart products. As one of micromachining processes, CNC micro blanking machine is proposed as basic technology to fabricate the component with miniaturized dimension. In this study, the validation between theoretical input on the program control and mechanical motion is conducted to significantly reduce the gap between actual carriage motion and G-Code motion. The average deviation of actual velocity on post calibration is determined to be $10.8 \mathrm{~mm} / \mathrm{min}$, while for carriage displacement for $\mathrm{X}, \mathrm{Y}$, and $\mathrm{Z}$ axes are $-0.0191 ;-0,0087$; and $-0.0005 \mathrm{~mm}$, respectively. Based on the analysis has been performed, it can be concluded that the imprecision is caused by the geometrical deviation of carriage (linear guide), so, the carriage movement is hindered by the deviation.
\end{abstract}

\section{Introduction}

Size and weight reduction of industrial products has been continuously developed, therefore, the need of machines for making high-precision products with good cutting quality is increased [1]. As one of the important control systems, CNC (Computer Numerically Controlled) is largely applied to control the cutting machine operation [2]. Generally speaking, this system is relatively similar with the conventional one [3]. The main different of these systems is that $\mathrm{CNC}$ plays the manual operator roles on conventional machining, such as tool path setting, cutting operation, and linking operation.

The desktop computer can be used as a CNC-machine-controller device by using Artsoft Mach3 software[4]. This works on Windows PC to control the motor (stepper and servo) motion by changing the G-Code. Mach3 is not only compatible with milling and lathe operation but also developed for several other CNC-based machines, such as shearing machine, plasma cutting, electrical discharge machining (EDM), water jet machining, and laser cutting. The software contains program-adding feature which is able to add the special function such as ATC (automatic tool changer).

\footnotetext{
* Corresponding author: didin.zakariya.ft@um.ac.id
} 
This study aims to develop automatic-control-based tool press machine using CNC system. The validation of mechanic-control system is further discussed in this study. The machine development is essential by considering the advantages of proposed microblanking machine which is having lower cost and higher productivity compared with micro-drilling and EDM in case of micro-hole cutting operation[5]. On the other hand, the CNC system by utilizing Artsoft Mach3 will not only achieve good precision and accuration level, but also minimize the alignment setting between punch and die. By setting tool optimization, the capacity can be increased, therefore, the production cost can be consequently suppressed.

\section{Mechanical design of the CNC micro blanking machine}

This CNC micro blanking used stepper motor as shown on Figure 1. The stepper motors having model of 57BYGHM604 were utilized as the main driver of table and bed motion on $\mathrm{X}, \mathrm{Y}$, and $\mathrm{Z}$ axes in world coordinate system (WCS). On the machine, the $\mathrm{X}, \mathrm{Y}$, and $\mathrm{Z}$ axes are defined as longitudinal direction of the table motion, cross direction of the table motion, and vertical direction of punch motion, respectively. The stepper motor played an important role to convert the electrical pulse to be step motion by using the driver. The stepper motor rotation will be transmitted to the ball-screw shaft connected with the coupling, where the main rotation will be converted to be straight motion of machine table and bed.

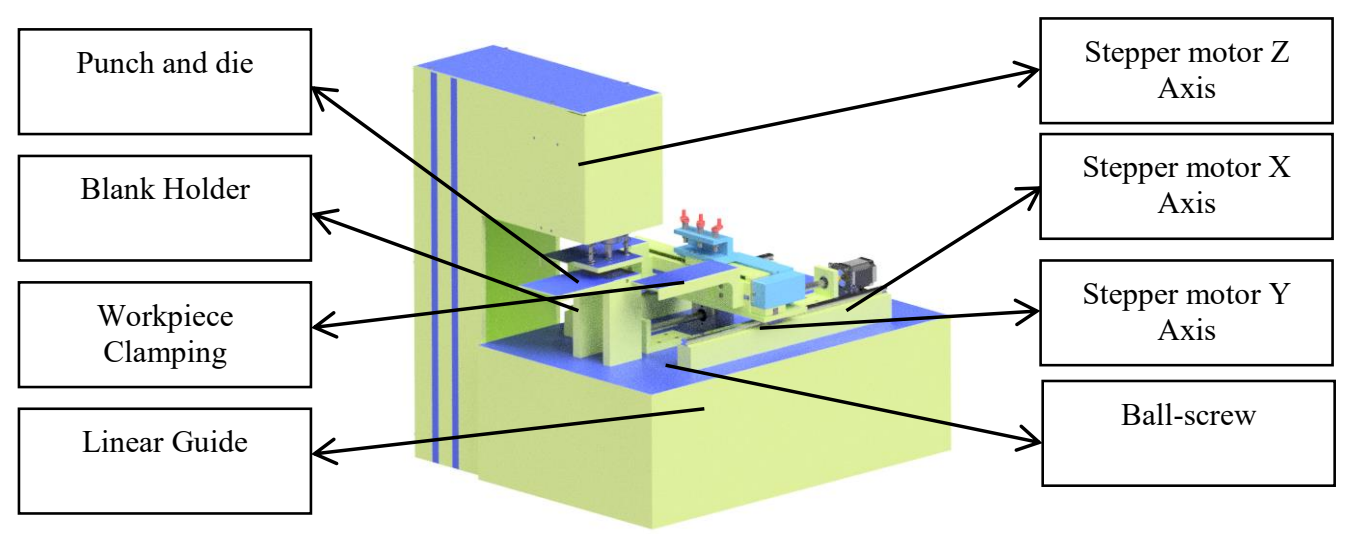

Fig. 1. CNC micro blanking machine.

\section{Control system for design architectural}

The entire system of the CNC micro-blanking machine contains three main parts, which are mechanical construction, electrical hardware, and computer (Figure 2a). The machine was operated by using Artsoft Mach3 (Figure 2b) having role to control the motor on carriage motion. For moving the carriage, the operator can manually drive or give the command by introducing G-Code, which is subsequently changed to be signal or pulse, so, the stepper motor can be rotated. 


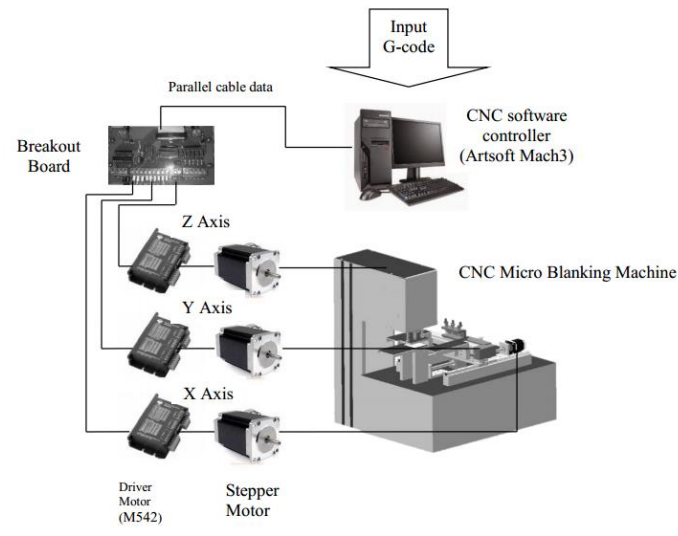

(a)

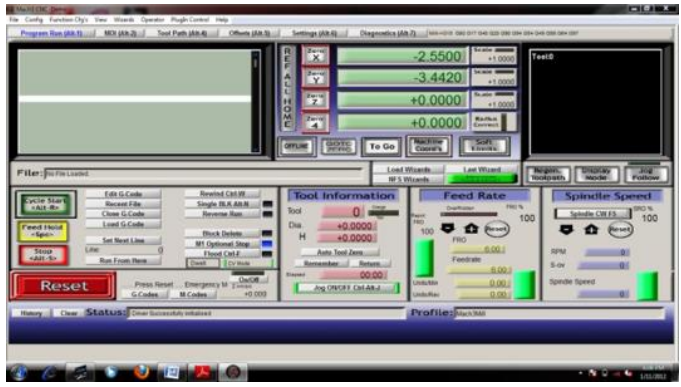

(b)

Fig. 2. (a) Illustration of control and mechanical system of CNC Micro Blanking Machine; (b) Artsoft Mach3 user interface.

\section{Investigation of the mechanics and control characteristics}

\subsection{Cutting velocity measurements}

\subsubsection{Punch velocity measurement using tachometer}

The measurement was carried out to analyze the precision of punch motion rate $(\mathrm{Z}$ axis carriage) by velocity input on Artsoft Mach3 compared with the actual motion. Velocity measurement validation was done by using digital tachometer with end effector in the form of roller coupled with ball-screw connector. This was conducted by measuring the motion simulation on $\mathrm{Z}$ axis carriage with point to point command on Artsoft Mach3. 14 variations of punch velocity were used in the experiment with the distance of $20 \mathrm{~mm}$, afterwards, the velocity value was observed by using tachometer. The results are listed as shown on Table 1.

Based on the table 1, it is obvious that all of punch velocities are not suitable with the command has been conducted. The deviation average is determined at $-44.4 \mathrm{~mm} / \mathrm{min}$, which negative (-) sign shows that actual punch velocities need to be reduced to obtain the expected velocities. 
Table 1. Punch velocity measurement.

\begin{tabular}{|c|c|c|c|c|c|c|c|}
\hline \multirow[t]{2}{*}{ No. } & \multirow{2}{*}{$\begin{array}{c}\text { v Program } \\
(\mathrm{mm} / \mathrm{min})\end{array}$} & \multirow{2}{*}{$\begin{array}{c}\mathrm{s} \\
(\mathbf{m m})\end{array}$} & \multicolumn{2}{|c|}{$\begin{array}{l}\text { Measuring } \\
\text { with } \\
\text { Tachometer }\end{array}$} & \multirow{2}{*}{$\begin{array}{l}v \text { actual } x \\
2,35 \text { (before } \\
\text { calibration) }\end{array}$} & \multirow{2}{*}{$\begin{array}{c}\text { Velocity } \\
\text { deviation } \\
(\mathrm{mm} / \mathrm{min})\end{array}$} & \multirow{2}{*}{$\begin{array}{l}\text { Average } \\
\text { deviation } \\
(\mathrm{mm} / \mathrm{min})\end{array}$} \\
\hline & & & RPM & $\begin{array}{l}\text { x } 5 \\
\text { mm }\end{array}$ & & & \\
\hline 1 & 10 & 20 & 0.8 & 4 & 9.4 & 0.6 & \multirow{14}{*}{-44.4} \\
\hline 2 & 30 & 20 & 2.5 & 12.5 & 29.4 & 0.6 & \\
\hline 3 & 50 & 20 & 4.5 & 22.5 & 52.9 & -2.9 & \\
\hline 4 & 70 & 20 & 6.1 & 30.5 & 71.7 & -1.7 & \\
\hline 5 & 900 & 20 & 85 & 425 & 998.8 & -98.8 & \\
\hline 6 & 1100 & 20 & 98 & 490 & 1151.5 & -51.5 & \\
\hline 7 & 1300 & 20 & 116 & 580 & 1363.0 & -63.0 & \\
\hline 8 & 1500 & 20 & 131 & 655 & 1539.3 & -39.3 & \\
\hline 9 & 1700 & 20 & 150 & 750 & 1762.5 & -62.5 & \\
\hline 10 & 1900 & 20 & 165 & 825 & 1938.8 & -38.8 & \\
\hline 11 & 2100 & 20 & 184 & 920 & 2162.0 & -62.0 & \\
\hline 12 & 2300 & 20 & 202 & 1010 & 2373.5 & -73.5 & \\
\hline 13 & 2500 & 20 & 218 & 1090 & 2561.5 & -61.5 & \\
\hline 14 & 2600 & 20 & 227 & 1135 & 2667.3 & -67.3 & \\
\hline
\end{tabular}

Where: $\quad$ Ratio $2,35: \varnothing$ Tachometer/ø measured shaft $(31.7 / 13.5=2.35)$

x $5 \mathrm{~mm}$ : ball-screw lead

\subsubsection{Punch Velocity Calibration by using Axis Calibration}

In this case, the calibration of punch velocity through axis calibration was done to investigate the distance input gap between the program and actual movement of carriage. The sequences of punch velocity calibration is stated as follows:

a. The measurement is conducted by introducing motion command at the distance of 1 $\mathrm{mm}$ with the punch velocities of 100,500,1000, 2000, and $2600 \mathrm{~mm} / \mathrm{min}$ for each axis on Artsoft Mach3 by typing in command window.

b. Inputted NC-Code into the computer was translated to be command signal transmitted from $\mathrm{PC}$ to microcontroller for controlling the motion of machine end effector in form of the carriage on $\mathrm{X}, \mathrm{Y}$, and $\mathrm{Z}$ axes independently.

c. Dial indicator placed on the carriage for each axis was utilized for calibration test. The results of carriage displacement are listed on Table 2.

From the results shown on Table 2, it indicates that if the displacement set on the program is determined as $1 \mathrm{~mm}$, the actual carriage displacement is observed to be $1.3 \mathrm{~mm}$. The results implied the small gap between the actual distance with the program input had been set having an average of $0,3 \mathrm{~mm}$. Consequently, the alignment on Artsoft Mach3 feature need to be conducted to reach a better calibration, called axis calibration, as shown on Figure 3. 
Table 2. Axis calibration result

\begin{tabular}{|c|c|c|c|c|c|c|c|c|}
\hline \multirow[b]{2}{*}{ No. } & \multirow[b]{2}{*}{ Axis } & \multirow{2}{*}{$\begin{array}{c}\mathrm{v} \\
(\mathrm{mm} / \mathrm{min} \\
)\end{array}$} & \multirow{2}{*}{$\mathrm{s}(\mathrm{mm})$} & \multicolumn{3}{|c|}{ Measurement movement } & \multirow{2}{*}{$\begin{array}{c}\text { Average } \\
\text { movement } \\
(\mathrm{mm})\end{array}$} & \multirow{2}{*}{$\begin{array}{c}\text { Average } \\
\text { deviation } \\
\text { movement }\end{array}$} \\
\hline & & & & 1st Test & 2nd Test & 3 th test & & \\
\hline 1 & \multirow{5}{*}{$\mathrm{X}$} & 100 & 1 & 1.32 & 1.30 & 1.30 & 1.31 & \multirow{5}{*}{0.31} \\
\hline 2 & & 500 & 1 & 1.31 & 1.32 & 1.32 & 1.32 & \\
\hline 3 & & 1000 & 1 & 1.32 & 1.32 & 1.31 & 1.32 & \\
\hline 4 & & 2000 & 1 & 1.31 & 1.30 & 1.33 & 1.31 & \\
\hline 5 & & 2600 & 1 & 1.30 & 1.30 & 1.32 & 1.31 & \\
\hline 1 & \multirow{5}{*}{$\mathrm{Y}$} & 100 & 1 & 1.32 & 1.29 & 1.30 & 1.30 & \multirow{5}{*}{0.30} \\
\hline 2 & & 500 & 1 & 1.30 & 1.29 & 1.30 & 1.30 & \\
\hline 3 & & 1000 & 1 & 1.30 & 1.30 & 1.30 & 1.30 & \\
\hline 4 & & 2000 & 1 & 1.32 & 1.32 & 1.31 & 1.32 & \\
\hline 5 & & 2600 & 1 & 1.30 & 1.30 & 1.30 & 1.30 & \\
\hline 1 & \multirow{5}{*}{ Z } & 100 & 1 & 1.30 & 1.30 & 1.29 & 1.30 & \multirow{5}{*}{0.30} \\
\hline 2 & & 500 & 1 & 1.31 & 1.32 & 1.30 & 1.31 & \\
\hline 3 & & 1000 & 1 & 1.32 & 1.31 & 1.32 & 1.32 & \\
\hline 4 & & 2000 & 1 & 1.30 & 1.30 & 1.30 & 1.30 & \\
\hline 5 & & 2600 & 1 & 1.30 & 1.30 & 1.30 & 1.30 & \\
\hline
\end{tabular}

Where: $\mathrm{s}$ : travel distance $(\mathrm{mm})$

$\mathrm{v}$ : punch velocity $(\mathrm{mm} / \mathrm{min})$

$\mathrm{t}:$ time $(\mathrm{min})$

Figure 3 shows the axis calibration steps by using Artsoft Mach3. On the $3^{\text {rd }}$ step, the axis will be calibrated is chosen because this calibration can be conducted only for each axis. Afterwards, the adjustment is needed to move the axis as desired (in this case, the axis was shifted for $1 \mathrm{~mm}$ ). After the axis stops, the actual axis displacement resulted from previous calibration is set to be $1.3 \mathrm{~mm}$ for each axis. By setting the actual motion occurred, therefore, the software will automatically count the step value of tunning motor.

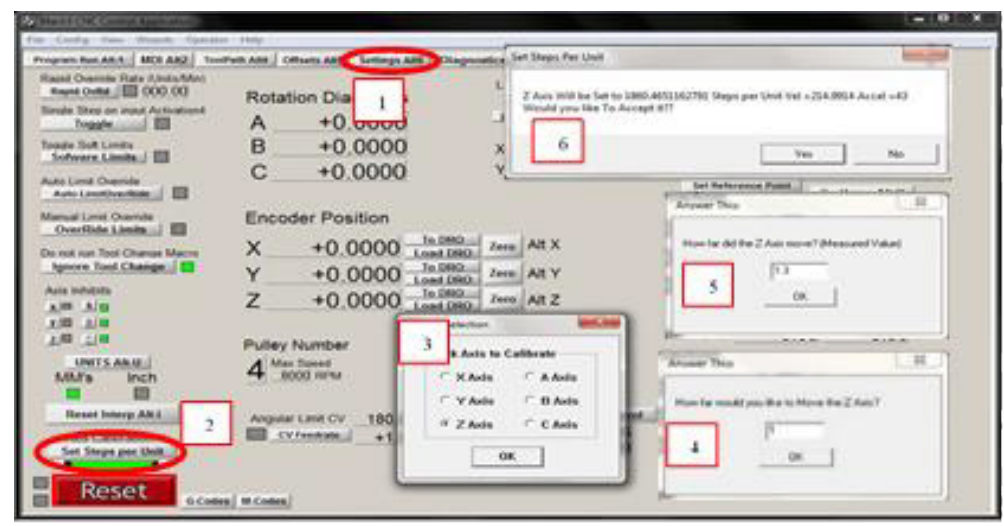

Fig 3. Velocity calibration.

In this case, the motor motion or motor rotation will be increased, because for achieving the greater actual displacement distance compared with the theoretical displacement, therefore, stepper motor will suit the rotation. Furthermore, the calibration results were reinvestigated by using tachometer. The post-calibration punch velocity test results are listed on Table 3. 
Table 3. Post-calibration punch velocity test result.

\begin{tabular}{|c|c|c|c|c|c|c|c|}
\hline \multirow[t]{2}{*}{ No. } & \multirow{2}{*}{$\begin{array}{c}\text { v Program } \\
(\mathrm{mm} / \mathrm{min})\end{array}$} & \multirow{2}{*}{$\begin{array}{c}\mathrm{s} \\
(\mathrm{mm})\end{array}$} & \multicolumn{2}{|c|}{$\begin{array}{c}\text { Measuring } \\
\text { with } \\
\text { Tachometer }\end{array}$} & \multirow{2}{*}{$\begin{array}{l}v \text { actual } x \\
2,35 \text { (after } \\
\text { calibration) }\end{array}$} & \multirow{2}{*}{$\begin{array}{l}\text { Velocity } \\
\text { Deviation } \\
(\mathbf{m m} / \mathbf{m i n})\end{array}$} & \multirow{2}{*}{$\begin{array}{l}\text { Average } \\
\text { deviation } \\
(\mathrm{mm} / \mathrm{min})\end{array}$} \\
\hline & & & RPM & $\begin{array}{l}\text { x } 5 \\
\text { mm }\end{array}$ & & & \\
\hline 1 & 10 & 20 & 0.8 & 4 & 9.4 & 0.6 & \multirow{14}{*}{10.8} \\
\hline 2 & 30 & 20 & 2.7 & 13.5 & 31.7 & -1.7 & \\
\hline 3 & 50 & 20 & 4.6 & 23 & 54.1 & -4.1 & \\
\hline 4 & 70 & 20 & 6.5 & 32.5 & 76.4 & -6.4 & \\
\hline 5 & 900 & 20 & 80.5 & 402.5 & 945.9 & -45.9 & \\
\hline 6 & 1100 & 20 & 93 & 465 & 1092.8 & 7.3 & \\
\hline 7 & 1300 & 20 & 108 & 540 & 1269.0 & 31.0 & \\
\hline 8 & 1500 & 20 & 126 & 630 & 1480.5 & 19.5 & \\
\hline 9 & 1700 & 20 & 146 & 730 & 1715.5 & -15.5 & \\
\hline 10 & 1900 & 20 & 161 & 805 & 1891.8 & 8.3 & \\
\hline 11 & 2100 & 20 & 176 & 880 & 2068.0 & 32.0 & \\
\hline 12 & 2300 & 20 & 192 & 960 & 2256.0 & 44.0 & \\
\hline 13 & 2500 & 20 & 208 & 1040 & 2444.0 & 56.0 & \\
\hline 14 & 2600 & 20 & 219 & 1095 & 2573.3 & 26.8 & \\
\hline
\end{tabular}

Where: $\quad$ Ratio $2,35: \varnothing$ Tachometer/ø measured shaft $(31.7 / 13.5=2.35)$ x $5 \mathrm{~mm}$ : ball-screw lead

The negative sign on velocity deviation shows that actual velocity indicated the excess punch velocity value, consequently, the actual punch velocity need to be decreased to obtain the suitable velocity with the theoretical one. On the table 3 , it is obvious that the post-calibration average punch velocity deviation is determined to be $10.8 \mathrm{~mm} / \mathrm{min}$. Figure 4 shows the punch velocity comparison of program (theoretical), pre-calibration (actual), and post-calibration (actual).

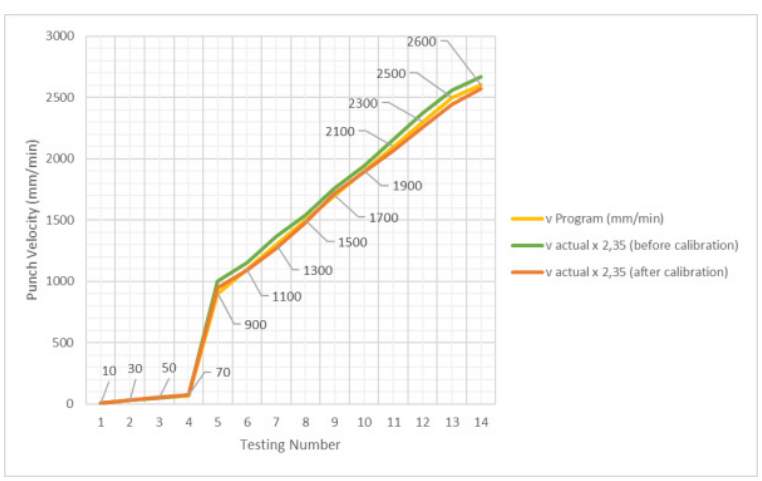

Fig 4. Graph of punch velocity test result comparison of pre-and post-calibration.

The actual punch velocity of pre- calibration and post-calibration is obtained by 14 times repetition using the fix displacement distance of $20 \mathrm{~mm}$. From Figure 4, it clearly shows the punch velocity deviation for at least $400 \%$ in average between pre- and postcalibration. On the other hand, the actual punch velocity difference of post-calibration remains closer to the theoretical velocity input having average gap of $10.8 \mathrm{~mm} / \mathrm{min}$.

These result differences are approximately caused by (1) the geometrical error from linear guide component due to the gap between each linear guide tip having $0.2 \mathrm{~mm}$; (2) the friction factor between linear guide nut and the linear guide itself. Both reasons are based on [6] that the position accuracy and movement orientation within the machining is 
determined by several factors, such as kinematics error, temperature effects, dynamic and cutting forces mismatch, inappropriate software and control systems, and tool wear. Among all of these problems, the geometrical error of component and cutting machine is determined as the biggest source of the imprecision.

\subsection{Repeatability Test}

Repeatability test is defined as the analysis of actual motion accuracy compared with the input value entered to the program. The objective of this control and mechanical system validation is to investigate the ability of $\mathrm{X}, \mathrm{Y}$, and $\mathrm{Z}$ axes carriage to take the initial position after performing some movement. The sequence of investigation is mentioned as follow:

a. Induce the motion command of 1, 2, 3, 4, and $5 \mathrm{~mm}$ on Artsoft Mach3 by filling the command window.

b. The test is carried out by drive a carriage for certain distance, then directly measure the carriage displacement when it moves back to initial position for each axis by using dial indicator.

c. Repeat the step 1 and 2 for motion command 2,3,4, and $5 \mathrm{~mm}$.

d. Conduct all the steps for at least 3 times.

Table 4. Repeatability test results.

\begin{tabular}{|c|c|c|c|c|c|c|c|c|}
\hline \multirow{2}{*}{ No. } & \multirow{2}{*}{ Axis } & \multirow{2}{*}{$\begin{array}{c}\mathbf{S} \\
(\mathrm{mm})\end{array}$} & \multicolumn{4}{|c|}{ Me as ure ment movement (mm) } & \multirow{2}{*}{$\begin{array}{l}\text { Deviation } \\
\quad(\mathrm{mm})\end{array}$} & \multirow{2}{*}{$\begin{array}{c}\text { Average } \\
\text { deviation for } \\
\text { each axis }(\mathrm{mm})\end{array}$} \\
\hline & & & 1st Test & 2nd Test & 3rd Test & 4th Test & & \\
\hline 1 & \multirow{5}{*}{$\mathrm{X}$} & 1 & 1.000 & 0.990 & 0.980 & 1.098 & 0.0170 & \multirow{5}{*}{-0.0191} \\
\hline 2 & & 2 & 1.970 & 1.980 & 1.970 & 1.940 & -0.0350 & \\
\hline 3 & & 3 & 2.940 & 2.930 & 2.930 & 2.970 & -0.0575 & \\
\hline 4 & & 4 & 3.980 & 3.970 & 4.010 & 3.990 & -0.0125 & \\
\hline 5 & & 5 & 5.010 & 4.980 & 4.990 & 4.990 & -0.0075 & \\
\hline 1 & \multirow{5}{*}{$\mathrm{Y}$} & 1 & 1.010 & 0.995 & 1.000 & 1.005 & 0.0025 & \multirow{5}{*}{-0.0087} \\
\hline 2 & & 2 & 2.010 & 1.970 & 2.005 & 2.000 & -0.0038 & \\
\hline 3 & & 3 & 2.970 & 2.970 & 2.980 & 3.010 & -0.0175 & \\
\hline 4 & & 4 & 3.985 & 3.990 & 3.980 & 3.970 & -0.0187 & \\
\hline 5 & & 5 & 5.010 & 5.000 & 4.980 & 4.985 & -0.0062 & \\
\hline 1 & \multirow{5}{*}{ Z } & 1 & 1.000 & 1.000 & 1.000 & 1.000 & 0.0000 & \multirow{5}{*}{-0.0005} \\
\hline 2 & & 2 & 2.000 & 2.000 & 2.000 & 2.000 & 0.0000 & \\
\hline 3 & & 3 & 3.000 & 3.000 & 3.000 & 3.010 & 0.0025 & \\
\hline 4 & & 4 & 4.000 & 4.010 & 3.990 & 4.000 & 0.0000 & \\
\hline 5 & & 5 & 4.980 & 5.000 & 5.000 & 5.000 & -0.0050 & \\
\hline
\end{tabular}

The repeatability test result indicates that every carriage experienced the deviation (backlash), as shown on Table 4. The average deviation of X, Y, and Z axes are -0.0191; 0.0087 ; and $-0.0005 \mathrm{~mm}$, respectively. The negative sign implies that the distance covered actually is less than the theoretical input distance entered to the program.

The larger backlash on $\mathrm{X}$ and $\mathrm{Y}$ axes was caused by misalignment between ball-screw and linear guide. Due to the important role of both components as carriage support, the carriage motion will be hindered if they perform the different distance. the demonstrated deviation result is still acceptable, because, the $\mathrm{X}$ and $\mathrm{Y}$ axis carriages for this CNC micro blanking machine prototype are only for alignment process between punch and die. The more precision counterpart is further needed for complex machining process. In contrary, the repeatability of $\mathrm{Z}$ axis carriage demonstrates the relatively small deviation $(-0.0005$ $\mathrm{mm}$ ). This is relevant with previous research statement that said a precision machine is determined when having the precision less than $5 \mu \mathrm{m}[7]$. 


\section{Conclusion}

From this study, it can be concluded that within manufacturing process, the measurement process, tolerances of paired component, process sequence, and assembly process play an importance role to determine the product quality. This aims to avoid the misalignment between the arrangement of machine component. The misalignment will generate the imprecision of the actual carriage movement compared with the theoretical input value on the program. Based on the result, it is obvious that CNC micro blanking shows the acceptable tolerance on $\mathrm{Z}$ axis (less than $5 \mu \mathrm{m}$ ) to fabricate micro-hole. For correction, the re-production of imprecision components is possibly needed.

Special acknowledgement is conveyed to LP2M Universitas Negeri Malang (UM) for managing the university's research fund (PNBP) 2018 on the letter number 21.2.6/UN32.14/LT/2018 as financial source and support for this study.

\section{References}

1. J. Jeswiet, M. Geiger, U. Engel, M. Kleiner, M. Schikora, J. Duflou, R. Neugebauer, P. Bariani, S. Bruschi. CIRP Journal Manufacturing Science Technology 1 : 2-17, doi:10.1016/j. cirpj.2008.06.005. (2008)

2. A.N.M. Amanullah, Murshiduzzaman, T. Saleha, R. Khan. Procedia Engineering 184. 163 - 170. (2017)

3. P.H. Daniel \& J.F. Kelly. Springer-Verlag New York, Inc. (2009)

4. ArtSoft Mach3. Art Fenerty and John Prenice. (2003)

5. M.W. Fu and W.L. Chan. Tooling and its Realization, Springer, New York. DOI 10.1007/978-1-4471-6326-8. (2014)

6. T. Rochim. ITB. Bandung. (2001)

7. Dornfeld, D. E. Lee, New York, Springer Science+Business Media (2008) 